This item was submitted to Loughborough's Research Repository by the author.

Items in Figshare are protected by copyright, with all rights reserved, unless otherwise indicated.

\title{
Influence of thermal conductivity on the dynamic response of magnetocaloric materials
}

PLEASE CITE THE PUBLISHED VERSION

http://dx.doi.org/10.1016/j.ijrefrig.2015.06.028

PUBLISHER

(c) Elsevier

VERSION

AM (Accepted Manuscript)

\section{PUBLISHER STATEMENT}

This work is made available according to the conditions of the Creative Commons Attribution-NonCommercialNoDerivatives 4.0 International (CC BY-NC-ND 4.0) licence. Full details of this licence are available at: https://creativecommons.org/licenses/by-nc-nd/4.0/

\section{LICENCE}

CC BY-NC-ND 4.0

\section{REPOSITORY RECORD}

Porcari, G., Kelly Morrison, F. Cugini, J.A. Turcaud, F. Guillou, A. Berenov, N.H. van Dijk, E. Brueck, L.F. Cohen, and M. Solzi. 2019. "Influence of Thermal Conductivity on the Dynamic Response of Magnetocaloric Materials”. figshare. https://hdl.handle.net/2134/18582. 


\title{
Influence of thermal conductivity on the dynamic response of magnetocaloric materials
}

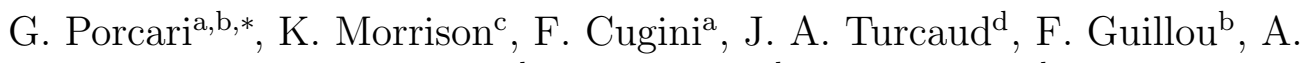 \\ Berenov $^{\mathrm{e}}$, N. H. van Dijk ${ }^{\mathrm{b}}$, E. H. Brück ${ }^{\mathrm{b}}$, L. F. Cohen ${ }^{\mathrm{d}}$, M. Solzi ${ }^{\mathrm{a}}$ \\ ${ }^{a}$ Department of Physics and Earth Sciences, University of Parma, 43124 Parma, Italy \\ ${ }^{b}$ Fundamental Aspects of Materials and Energy (FAME), Faculty of Applied Sciences, \\ Delft University of Technology, 2629 JB Delft, The Netherlands \\ ${ }^{c}$ Physics Department, Loughborough University, Loughborough, Leicestershire, LE11 \\ 3TU, UK \\ ${ }^{d}$ The Blackett Laboratory, Imperial College London, London SWraBZ, UK \\ ${ }^{e}$ Department of Materials, Imperial College London, London SWr2AZ, UK
}

\begin{abstract}
We compare the magnetocaloric effect of samples prepared with different thermal conductivities to investigate the potential of composite materials. By applying the magnetic field under operating conditions we test the material's response and compare this to heat transfer simulations in order to check the reliability of the adiabatic temperature change probe used. As a result of this study we highlight how the material's thermal conductivity influences $\tau$, the time constant of temperature change. This parameter ultimately limits the maximum frequency of a refrigerant cycle and offers fundamental information about the correlation between thermal conductivity and the magnetocaloric effect.
\end{abstract}

Keywords: first order magnetic transitions, magnetocaloric effect, thermal conductivity, time constant

\footnotetext{
${ }^{*}$ Corresponding author. Tel.: +39 0521905245

Email address: giacomo.porcari@fis.unipr.it (G. Porcari)
} 
PACS: 75.30.Sg, $75.30 . \mathrm{Kz}$

2000 MSC: 80A20, 74N20

\section{Introduction}

Minimization of energy consumption is currently one of the most demanding research challenges, motivating the development of new technical solutions to slow down climate change and the depletion of available resources. As a large amount of worldwide energy consumption can be attributed to cooling devices (Sandeman, 2011; Gutfleisch et al., 2011), the development of a new generation of more efficient and environmentally friendly refrigerators would therefore constitute a technological revolution.

Solid-state magnetic cooling is one such promising technology that has the potential to realize new, more efficient cooling devices without the need to use hydrofluorocarbon (HFC) greenhouse gases. The magnetocaloric effect (MCE), which constitutes the working principle of these machines, is an entropy $\left(\Delta s_{\mathrm{T}}\right)$ or a temperature $\left(\Delta T_{\mathrm{ad}}\right)$ change induced by a changing magnetic field under isothermal or adiabatic conditions, respectively (Pecharsky et al., 2001; Tishin and Spichkin, 2003; Smith et al., 2012). The Maxwell relations, which are commonly used to quantify this effect (Brück, 2005), show that the MCE is maximum in the neighbourhood of magnetic phase transitions. Back in 1997 the discovery of a giant magnetocaloric effect (GMCE) in $\mathrm{Gd}_{5}(\mathrm{Si}, \mathrm{Ge})_{4}$ compounds highlighted that large $\Delta s_{\mathrm{T}}$ values could be generated under an external field due to the contribution of latent heat (in this case originating from a structural phase change) (Pecharsky and Gschneidner, 1997). This idea is arguably the platform on which the current magnetocaloric commu- 
nity was built, and many other interesting first order materials have since been discovered (Tegus et al., 2002; Hu et al., 2001; Wada and Tanabe, 2001; Krenke et al., 2005; Trung et al., 2010; Sandeman, 2012).

The processes studied so far are generally solid-state phase transitions characterized by a specific latent heat of one to two orders of magnitude lower than the specific latent heats of vaporization seen in the HFC fluids. In order to develop a competitive device that pumps the same amount of heat as a commercial refrigerator whilst achieving a higher efficiency (for a similar mass of refrigerant), magnetocaloric materials would have to sustain thermodynamic cycles of a few Hertz compared to $0.03 \mathrm{~Hz}$ for small (1 - $1.5 \mathrm{~kW}$ cooling power) vapor compression refrigerators ${ }^{(1)}$. With this requirement in mind, the study of the material's response under prototypical operating conditions becomes increasingly important (Kuz'min, 2007; Lyubina et al., 2010; Lyubina, 2011; Bahl et al., 2008; Moore et al., 2009, 2013; Nielsen and Engelbrecht, 2012; Legait et al., 2014). An experimental characterization technique that is able to simulate real working conditions will therefore offer invaluable information about the reproducibility and dynamic response of a magnetocaloric material (Franco et al., 2012). The interplay between the material's thermal conductivity and the dynamic response of the magnetocaloric material to the applied magnetic field will determine the maximum achievable operation frequency (Lovell et al., 2014). In addition, magnetic field-induced structural fatigue is another feature that will need to be considered when engineering future materials.

\footnotetext{
${ }^{1}$ Technical data extracted from BITZER Software v6.4.3 rev.1353 and provided by Dr. M. Mazzani, researcher at Zanotti S.p.a. (private communication).
} 
Many of the most promising systems studied show first order phase transitions that are irreversible if exposed to the magnetic field changes typically achievable by permanent magnets. This self-limiting issue has motivated many groups to look for different controlling parameters such as electric field, pressure and stress in order to more easily drive these solid-solid phase transitions (Moya et al., 2013; Mañosa et al., 2010, 2013; Fähler et al., 2012; Ozbolt et al., 2014; Moya et al., 2014; Czernuszewicz et al., 2014). However, any future energy-conversion device based on one of these caloric effects, will also have to operate high frequency thermodynamic cycles. The development of good working systems will therefore follow a similar path to that already followed for magnetocaloric materials. In other words, studies on the relationship between the material's thermal conductivity and electro-, baro-, elasto-caloric effects together with investigation of the evolution of structural fatigue induced by the ongoing application of electric field or pressure or stress will be needed.

In this work we study the dynamic response to the external field of magnetocaloric materials prepared with different thermal conductivities. We start by presenting the outcomes of two $\mathrm{La}_{0.67} \mathrm{Ca}_{0.33} \mathrm{MnO}_{3}$ manganite samples. Our initial observations indicate that the shape of the thermodynamic cycles performed in these two cases is markedly different. To understand the origin of this behaviour we perform heat transfer simulations and repeat the same characterization for a gadolinium plate and two MnFePSi-based alloys, also engineered to have different thermal conductivities. 


\section{Experimental}

$\mathrm{La}_{0.67} \mathrm{Ca}_{0.33} \mathrm{MnO}_{3}$ (labelled LCMO) pellets were prepared from polycrystalline powders synthesized by the glycine nitrate process, as presented by Turcaud et al. (2013). This material, beyond its complex and fascinating behaviour across the metal-insulator transition (Turcaud et al., 2014), is interesting also for energy conversion applications since recently similar compositions showed promising results when tested in a refrigeration test device with the combination of a modest and reversible MCE and a good mechanical stability (Bahl et al., 2012). Here we compare the results of parent LCMO $\left(94 \%\right.$ dense, $k_{\mathrm{LCMO}}=1.35 \mathrm{Wm}^{-1} \mathrm{~K}^{-1}$ at $\left.\mathrm{T}_{\mathrm{C}}\right)$ with a composite system $(85 \%$ dense, 78 vol.\% of LCMO and 7 vol.\% of silver, labelled LCMO+Ag), where the thermal conductivity is enhanced by silver impregnation $\left(k_{\mathrm{LCMO}+\mathrm{Ag}}=\right.$ $2.2 \mathrm{Wm}^{-1} \mathrm{~K}^{-1}$ at $\mathrm{T}_{\mathrm{C}}$; (Turcaud et al., 2013)). The Curie temperature of these two systems lies at $\mathrm{T}_{\mathrm{C}}=258 \mathrm{~K}$.

The GMCE MnFePSi-based systems stand out amongst the most promising compounds for future applications (Dung et al., 2011; Guillou et al., 2014a,b). For comparison with the studied LCMO samples, the $\mathrm{Mn}_{1.27} \mathrm{Fe}_{0.68} \mathrm{P}_{0.48} \mathrm{Si}_{0.52}$ (labelled MnFePSi) composition was chosen as it exhibits a similar $\mathrm{T}_{\mathrm{C}}$ coupled with small hysteresis (1.8 K in $1 \mathrm{~T}$ ) ensuring the cyclability of the MCE (Dung et al., 2011). This sample was prepared by ball milling of elemental starting materials and solid-state reaction according to the same heat treatment as previously reported (Guillou et al., 2014a; Yibole et al., 2014). Part of this batch was also used to prepare a composite (20 wt.\% of epoxy) with a reduced thermal conductivity (labelled MnFePSi+epoxy).

Finally, gadolinium plates (99.9\% pure, purchased from Goodfellow) were 
also studied, as the benchmark material for application of the magnetocaloric effect (Sandeman, 2012).

All samples were parallelepipeds cut to similar dimensions (about $1.5 \times$ $3.0 \times 5.5 \mathrm{~mm}^{3}$ ) with a Buehler low speed diamond saw to minimize any geometrical contribution to their thermal transport properties.

To test the dynamic response of the materials, we used a homemade experimental setup that consists of a pneumatic linear actuator to insert and extract the temperature change probe (Fig. 1 a) between two regions with controlled temperature and magnetic field (Porcari et al., 2013). The temperature sensor used was a Lakeshore Cernox $^{\mathrm{TM}}$ thermoresistor (bare chip $)^{(2)}$. The temperature sensor was glued onto a fiberglass board (see Fig. 1 b) equipped with gold contacts to preserve it from mechanical stresses. The fiberglass board was fixed in a PEEK (Polyether ether ketone) housing, while the sensor chip was put downwards to protect the wires. A cavity in the PEEK avoids any contact between the surface of the sensor and the probe (Fig. $1 \mathrm{~b}$ ). It is worth noting that for these experiments the magnetic field in the two regions varied from $0.1 \mathrm{~T}$ to $1 \mathrm{~T}$, corresponding to a field change of $0.9 \mathrm{~T}$. In addition, application of the magnetic field was measured to take about $70 \mathrm{~ms}$ (rise time) to sweep through $90 \%$ of the full jump thus giving an average magnetic field ramp of about $10 \mathrm{Ts}^{-1}$, a value close to what would be expected in real prototypes.

These experiments, carried out in a low pressure of helium exchange gas ( $p \approx 1$ mbar), were designed to mimic a Brayton thermodynamic cycle (see Fig. 2). The four branches of the measurement cycles were: 1) the system at a selected sample temperature $\left(T_{1}\right)$ is inserted in the field region at a rate of 
a)

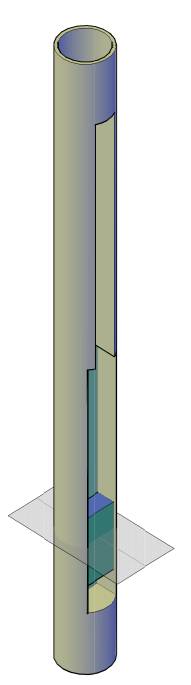

b)

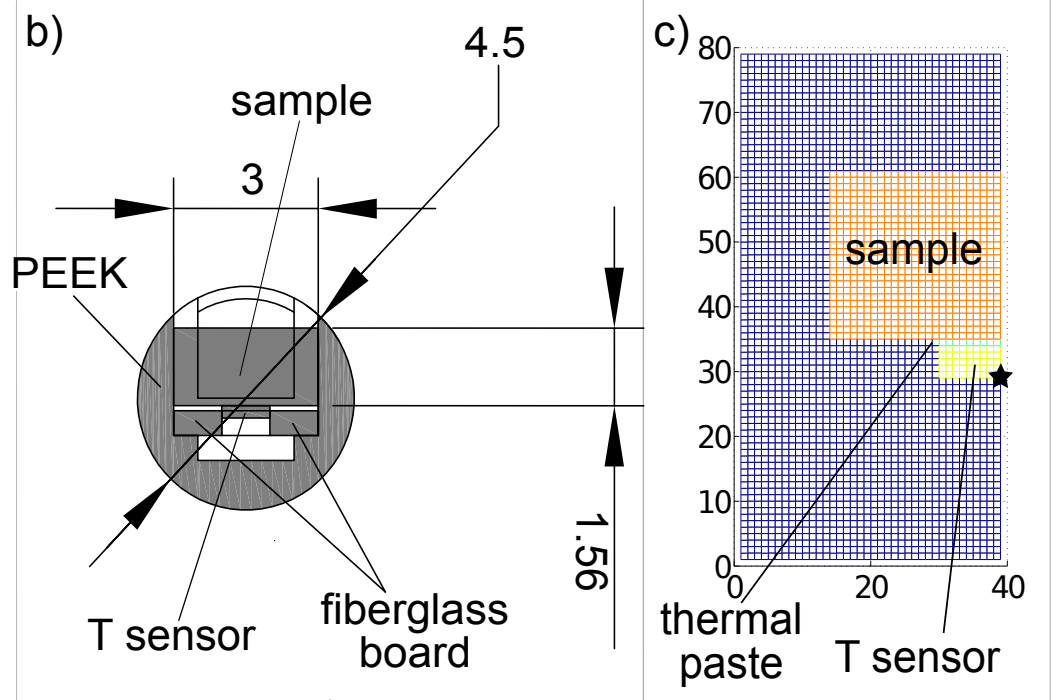

Figure 1: (Colour online) a) Temperature change probe with 2D section plane, b) 2D section in the sample-sensor position, c) Simulation mesh: the black star marks the node where the temperature was sampled.

approximately $\left.10 \mathrm{Ts}^{-1}(\longrightarrow \triangle) ; 2\right)$ the temperature decreases under isofield conditions from $T_{1}+\Delta T_{\text {ad }}$ to $\left.T_{2}(\triangle \longrightarrow \bigcirc) ; 3\right)$ once the temperature reaches $T_{2}$ the system is extracted to the low field region (at approximately $10 \mathrm{Ts}^{-1}$; $\bigcirc \longrightarrow \mathbf{\Lambda})$; and 4) the temperature relaxes to $T_{1}$ at constant field

The in-field and out-of-field regions were kept $10 \mathrm{~K}$ below and above the cycle average $\left(\frac{T_{1}+T_{2}}{2}\right)$, respectively, to enhance the relaxation of the system during the isofield branches. Isothermal entropy changes were obtained from magnetization data using both isotherm and isofield curves. Thermal conductivity measurements were carried out using the thermal transport option of the Physical Property Measurement System (PPMS) in the continuous measurement mode (two-probe lead configuration). Finally, the Archimedes method was used to determine the sample densities. 
Heat transfer simulations were carried out using the finite-difference explicit method (Incropera et al., 2007). The simulation represented half of a 2D section of the sample and sensor (Fig. 1b) with a layer of thermoconductive grease (Arctic Silver Ceramique) in between; the mesh (Fig. 1c) was a compromise between a good spatial resolution $(\Delta x=60 \mu \mathrm{m})$ and a reasonable time step $(\Delta t=50 \mu \mathrm{s})$. The temperature was sampled at the middle of the lower sensor face, where the Cernox film lies ${ }^{(2)}$ (Fig. 1c). The temperature sensor was considered as a full piece of sapphire $\left(\rho=4000 \mathrm{kgm}^{-3}\right.$, $\left.\mathrm{k}=25 \mathrm{Wm}^{-1} \mathrm{~K}^{-1}\right)$; the density of the thermal conductive paste, $\rho=2600$ $\mathrm{kgm}^{-3}$, was specified by the company and we chose $\mathrm{k}=3 \mathrm{Wm}^{-1} \mathrm{~K}^{-1}$ (an average between the value originally specified by the company $5 \mathrm{Wm}^{-1} \mathrm{~K}^{-1}$ and lower values reported (Narumanchi et al., 2008)). The specific heat of sapphire, used as a calorimetry reference, is well known (we considered 760 $\mathrm{Jkg}^{-1} \mathrm{~K}^{-1}$ at room temperature and $680 \mathrm{Jkg}^{-1} \mathrm{~K}^{-1}$ at $260 \mathrm{~K}$ ); the specific heat of the thermal paste was directly measured $\left(700 \mathrm{Jkg}^{-1} \mathrm{~K}^{-1}\right.$ at $260 \mathrm{~K}$ and 725 $\mathrm{Jkg}^{-1} \mathrm{~K}^{-1}$ at $\left.290 \mathrm{~K}\right)$. We approximated the layer of thermal conductive paste to be $1 / 5$ of the sensor thickness $(60 \mu \mathrm{m})$. By repeating the simulations with a layer twice as thick (which corresponds to $60 \mu \mathrm{m}$ of paste with $\mathrm{k}=1.5$ $\mathrm{Wm}^{-1} \mathrm{~K}^{-1}$ ) we observed an increase of the time constant by $0.02 \mathrm{~s}$, whilst a $30 \mu \mathrm{m}$ layer (or $60 \mu \mathrm{m}$ of paste, with $\mathrm{k}=6 \mathrm{Wm}^{-1} \mathrm{~K}^{-1}$ ) decreased the time constant by $0.01 \mathrm{~s}$. The MCE was considered as a heat source $(\dot{q})$ developing in the material for an amount of time determined by the magnetic field rise time $\left(\Delta t_{\text {field }}\right): \dot{q}=\frac{\Delta s_{T} \cdot \rho \cdot T_{C}}{\Delta t_{\text {field }}}$. The results of the finite-difference method were also confirmed by independent simulations carried out by means of the 


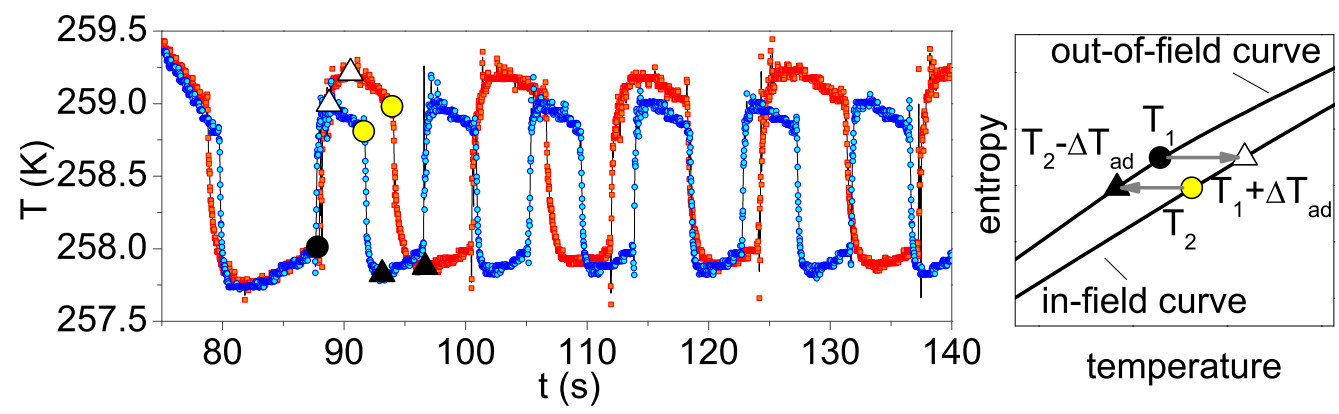

Figure 2: (Colour online) Left plot: Results of the thermomagnetic cycles on the parent (red squares) and Ag-filled (blue circles) LCMO, for a magnetic field change of $0.9 \mathrm{~T}$. The two measurements were performed under the same experimental conditions. Right plot: The starting points of each branch of the thermodynamic cycle, $T_{1}, T_{1}+\Delta T_{\mathrm{ad}}, T_{2}$ and $T_{2}-\Delta T_{\text {ad }}$ (as defined in the text), are also shown.

COMSOL Multiphysics finite-element-based Heat Transfer module.

\section{Results and Discussion}

The experimental thermodynamic cycles for the two LCMO samples cycled between $\mu_{0} H=0.1 \mathrm{~T}$ and $\mu_{0} H=1 \mathrm{~T}$ are shown in Fig. 2 .

The first detail which stands out from Fig. 2 is the different MCE of the two materials: the adiabatic temperature change, $\Delta T_{\mathrm{ad}}$, of the parent (red squares) and Ag-filled (blue circles) LCMO are 1.20 $\pm 0.15 \mathrm{~K}$ and $1.00 \pm 0.15$ $\mathrm{K}$, respectively. In both measurements a small irreversibility of about 0.15 $\mathrm{K}$ can be seen on comparison to the very first cooling branch $(t \approx 80 \mathrm{~s})$. We note here that the MCE measured in the parent compound $\left(\Delta T_{\mathrm{ad}}=\right.$ $1.2 \mathrm{~K}$ ) is in agreement with the values reported in other similar perovskites

\footnotetext{
${ }^{2}$ Cernox $^{\text {TM }}$ datasheet at http://www.lakeshore.com/Documents/LSTC_Cernox_l.pdf for information about the bare chip.
} 
(Bahl et al., 2012), although it turns out to be smaller than the pioneering measurements of Dinesen et al. (2005). The MCE we would expect for the Ag-filled LCMO is determined by the balance of the heat capacities of the mass fractions of silver and LCMO constituting the composite: $\Delta T_{a d}{ }^{L C M O+A g}=\Delta T_{a d}{ }^{L C M O} \frac{c_{p}^{L C M O} m^{L C M O}}{c_{p}^{L C M O} m^{L C M O}+c_{p}^{A g} m^{A g}}=1.15 \mathrm{~K}$, where we used $\Delta T_{\mathrm{ad}}{ }^{\mathrm{LCMO}}=1.20 \mathrm{~K}$ (experimental value), the specific heat of pure silver $\left(c_{\mathrm{p}}^{\mathrm{Ag}}=230 \mathrm{Jkg}^{-1} \mathrm{~K}^{-1}\right)$ was taken from literature (Furukawa et al., 1968) and $m^{\mathrm{LCMO}}=0.88$ and $m^{\mathrm{Ag}}=0.12$ as the mass fractions of LCMO and silver in the composite. $\Delta T_{\mathrm{ad}}^{\mathrm{LCMO}+\mathrm{Ag}}=1.15 \mathrm{~K}$ is slightly higher than the outcome of the measurement but still within error. The entropy changes, obtained from isothermal magnetization curves amount to $\Delta s_{\mathrm{T}}=3.8 \mathrm{Jkg}^{-1} \mathrm{~K}^{-1}$ and $3.4 \mathrm{Jkg}^{-1} \mathrm{~K}^{-1}$ for the parent and the composite LCMO, respectively (see Table 1). The cycles were also performed between different temperatures $\left(T_{1}\right.$ and $T_{2}$ ); the data reported in Fig. 2 represent the maximum MCE observed in these two materials.

As can be observed in Fig. 2 the cycle period of the Ag-filled LCMO was substantially smaller (9 s) than that of the parent system (12 s). Since the relaxation branches take about the same amount of time in the two experiments, it can be concluded that the time delay for the parent LCMO was mainly accrued during its adiabatic branches.

Fig. 2 however is not sufficient to understand why the Ag-filled LCMO showed a higher cycle frequency. To emphasise this aspect, in Fig. 3 we zoom in and show superimposed onto one another a half cycle period for each LCMO sample normalised to their maximum $\Delta T_{\mathrm{ad}}$. A good parameter to describe this difference is the time constant $\tau$ of the adiabatic temperature 
change.

In this work, for each material we compare two time constants: 1) that obtained by fitting the experimental data (experimental time constants) to take into account both the heat transfer between the magnetocaloric material and the sensor and any possible intrinsic time constant associated with the material's MCE itself, and 2) that obtained from heat transfer simulations (simulated time constants) the aim of which is to estimate the time needed for heat transfer between the magnetocaloric material and the sensor. The simulated time constant indicates what we would expect if the material was reacting instantaneously (without any delays) to the external field ramp.

In order to determine the experimental $\tau$ for $\mathrm{LCMO}$ and $\mathrm{LCMO}+\mathrm{Ag}$ the data of Fig. 3 were fitted (black dotted lines) using the following exponential function (Kamarád et al., 2012): $\frac{\Delta T(t)}{\Delta T_{\max }}=1-e^{-\frac{t}{\tau}}$ (the time constants obtained by fitting the experimental data are indicated in Fig. 3). At first we simulated the heat transfer across all sections of the probe (as drawn in Fig. $1 \mathrm{~b})$ to compare to the outcomes obtained by fitting the experimental data with: $\frac{\Delta T(t)}{\Delta T_{\max }}=\left(1-e^{-\frac{t}{\tau_{1}}}\right) e^{-\frac{t}{\tau_{2}}}$, where $\tau_{1}$ is the magnetocaloric (or adiabatic) time constant we refer to in this work, and $\tau_{2}$ is the relaxation (or isofield) time constant. We thereafter decided to simulate and fit just the adiabatic branches for two reasons: 1) In our experiments the relaxation branches lasted just a few seconds (about 5 s, see Fig. 2 a) whist their time constants $\left(\tau_{2}\right)$ were tens of seconds (i.e. the consequence of fitting the relaxation branches was that the outcomes of these fits both $\tau_{1}$ and $\tau_{2}$ were affected by large errors). 2) The time constants obtained from simulations carried out with or without the probe (fiberglass and PEEK) did not change 


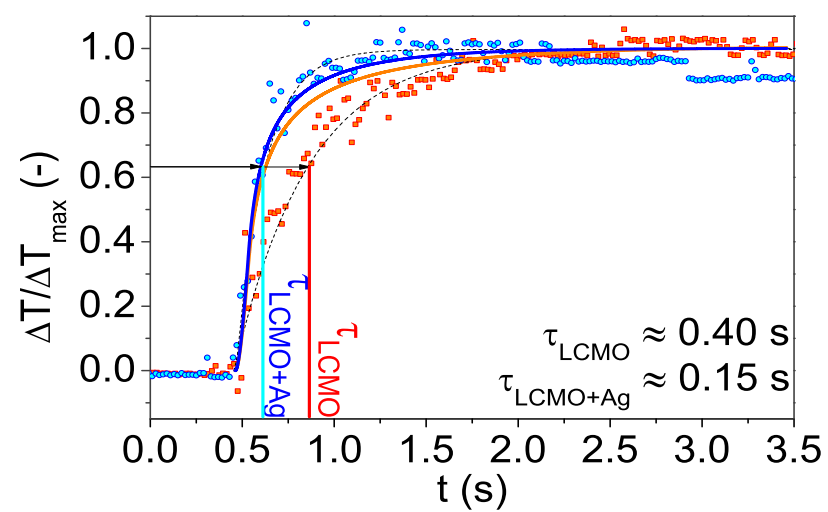

Figure 3: (Colour online) Half-cycles of the parent LCMO (red squares) and Ag-filled LCMO (blue circles) normalized to their maximum $\Delta T_{\text {ad }}$. The black dotted lines correspond to fits of the experimental data (see text). Orange and blue curves (light and dark gray in grayscale) are the simulated materials response for the parent (LCMO) and composite $(\mathrm{LCMO}+\mathrm{Ag})$ samples, respectively.

significantly (considering all the sections of the probe the time constants were about 0.015 s slower).

In Fig. 3 the simulated materials response is also shown (orange and blue curves for the parent (LCMO) and composite $(\mathrm{LCMO}+\mathrm{Ag})$ samples, respectively). These simulations are based on the thermal parameters only and agree well with experimental data for the composite $\left(\tau_{\text {sim }}=0.14 \mathrm{~s}, \tau_{\text {exp }}=\right.$ $0.15 \mathrm{~s})$ but not for the parent LCMO $\left(\tau_{\text {sim }}=0.165 \mathrm{~s}, \tau_{\text {exp }}=0.4 \mathrm{~s}\right)$. In order to understand whether our simulations are reliable, we tested other materials under the same experimental conditions and compared their dynamic behaviour with the outcomes of heat transfer simulations. We include in this work two MnFePSi-based samples, characterized by a sharp first-order Curie transition and different thermal conductivities, in addition to a gadolinium 
sample.

The adiabatic temperature change measured for the gadolinium sample $\left(k_{\mathrm{Gd}}=10 \mathrm{Wm}^{-1} \mathrm{~K}^{-1}\right)$ was $\Delta T_{\mathrm{ad}}=2.10 \pm 0.15 \mathrm{~K}$, in agreement with previous work (Porcari et al., 2013): the time constant of its adiabatic branches corresponded to $\tau=0.11 \mathrm{~s}$. We measured $\Delta T_{\mathrm{ad}}=2.10 \pm 0.15 \mathrm{~K}$ for the parent MnFePSi for a magnetic field change of $1 \mathrm{~T}$, which is reasonable given recent reports on $\mathrm{Fe}_{2} \mathrm{P}$-based systems (Yibole et al., 2014). The thermal hysteresis of this material, measured from magnetization isofields at a sweep rate of 1 $\mathrm{Kmin}^{-1}$, is $1.8 \mathrm{~K}$; its thermal conductivity across the first-order transition was determined to be $k_{\mathrm{MnFePSi}}=3.5 \mathrm{Wm}^{-1} \mathrm{~K}^{-1}$ and the time constant associated with the temperature change $\tau=0.12 \mathrm{~s}$. A second composite material was also prepared to test a $\mathrm{Fe}_{2} \mathrm{P}$-based system with a lower thermal conductivity than its parent alloy: a mixture of MnFePSi and epoxy (20 wt.\% and $\left.k_{\mathrm{MnFePSi}+\text { epoxy }}=1.25 \mathrm{Wm}^{-1} \mathrm{~K}^{-1}\right)$. This material exhibited a significantly larger thermal hysteresis compared to its parent compound $\left(\Delta T_{\text {hyst }}=3.3 \mathrm{~K}\right.$ in $1 \mathrm{~T}$ measured from magnetization isofields at a sweep rate of $1 \mathrm{Kmin}^{-1}$ ). This feature may mean that the epoxy acts not just as a binder for the magnetocaloric particles, but also perturbs the thermodynamic properties of the magnetic transition. This larger hysteresis, together with the passive matrix of the epoxy, resulted in a large reduction of the reversible MCE of this composite material $\left(\Delta T_{\mathrm{ad}}=0.90 \pm 0.15 \mathrm{~K}\right.$ for $\left.\mu_{0} \Delta H=1 \mathrm{~T}\right)$.

Before discussing the results obtained for these five materials, it is necessary to understand which quantities play a role in the $\tau$ that we measure and simulate. To do this, we calculate the time constant of an equivalent electric circuit where the sample + sensor are two capacitors $\left(C_{1}\right.$ and $\left.C_{2}\right)$ connected 
Table 1: Thermodynamic properties of the materials in this study in the transformation region: density, $\rho$; specific heat, $c_{\mathrm{p}}$; thermal conductivity, $k$; entropy change, $\Delta s_{\mathrm{T}}$; temperature change, $\Delta T_{\text {ad }}$; and experimental time constant, $\tau$. The estimated errors are given in brackets. The specific heat reported is the out-of-field peak value of the heating branch of the transition. These numbers show the different discontinuous character of the magnetic phase transition in each case.

\begin{tabular}{ccccccc}
\hline Material & $\rho$ & $\begin{array}{c}c_{\mathrm{p}} \\
\left(\mathrm{kgm}^{-3}\right)\end{array}$ & $\begin{array}{c}k \\
\left(\mathrm{Jkg}^{-1} \mathrm{~K}^{-1}\right)\end{array}$ & $\begin{array}{c}\Delta s_{\mathrm{T}} \\
\left(\mathrm{Wm}^{-1} \mathrm{~K}^{-1}\right)\end{array}$ & $\begin{array}{c}\Delta T_{\mathrm{ad}} \\
\left(\mathrm{Jkg}^{-1} \mathrm{~K}^{-1}\right)\end{array}$ & $\begin{array}{c}\tau \\
(\mathrm{K})\end{array}$ \\
\hline \hline LCMO & 5600 & 750 & 1.35 & $3.8^{a}$ & $1.20 \pm 0.15^{b}$ & $0.40 \pm 0.05$ \\
LCMO+Ag & 5400 & 650 & 2.2 & $3.4^{a}$ & $1.00 \pm 0.15^{b}$ & $0.15 \pm 0.03$ \\
gadolinium & 7900 & 340 & 10 & $3^{a}$ & $2.10 \pm 0.15^{a}$ & $0.11 \pm 0.03$ \\
MnFePSi & 5500 & 1500 & 3.5 & $12^{a}$ & $2.10 \pm 0.15^{a}$ & $0.12 \pm 0.03$ \\
MnFePSi+epoxy & 3200 & 1300 & 1.25 & $4.5^{a}$ & $0.90 \pm 0.15^{a}$ & $0.20 \pm 0.05$ \\
${ }^{a}$ In a $\mu_{0} \Delta H=1 \mathrm{~T}$ field span. & & & & &
\end{tabular}

by a resistor $(R)$. At the beginning of the transient the first capacitor (the sample: $C_{1}$ ) is fully charged whilst the second capacitor (the sensor: $C_{2}$ ) is discharged. The resistor takes into account the thermal resistances of the sample, thermal conductive paste, and sensor such that during this transient we will have:

$$
\frac{Q_{1}}{C_{1}}-R I=\frac{Q_{2}}{C_{2}}
$$

where $Q_{1}$ and $Q_{2}$ are the charges on the two capacitors, and I is the current flowing through the resistor. Based on the assumption that this is a closed system $\left(Q=Q_{1}+Q_{2}\right)$, the corresponding differential equation is:

$$
Q_{1}-\frac{C_{1} C_{2}}{C_{1}+C_{2}} R \frac{\partial Q_{1}}{\partial t}-\frac{C_{1}}{C_{1}+C_{2}} Q=0
$$

and $\tau=\frac{C_{1} C_{2}}{C_{1}+C_{2}} R$ is the time constant of the solution to this equa- 
tion. In our case $C_{1} \gg C_{2}$ (due to the relative sizes of the sample and sensor), which gives $\tau=\frac{C_{1} C_{2}}{C_{1}+C_{2}} R \approx C_{2} R$, that is, $\tau$ is independent of the material's heat capacity. Since we always used the same temperature sensor and thermoconductive paste, when we compare the time constants of different materials we can consider $R_{\text {paste }}$ and $R_{\text {sensor }}$ as constant values: $\tau \approx C_{2} R=C_{2}\left(R_{\text {sample }}+R_{\text {paste }}+R_{\text {sensor }}\right)=$ const $+C_{2} R_{\text {sample }}=$ const $+g C_{2} k^{-1}=\tau_{0}+a k^{-1}$, where $g$ is a geometrical factor that, by measuring samples of the same geometry, in this study was kept constant.

The simulated (triangles) and experimental (circles) time constants are shown in Fig. 4 as a function of thermal conductivity. We found that the function $\tau=\tau_{0}+a k^{-1}$ fits the simulated data particularly well, where $\tau_{0}=$ $80 \mathrm{~ms}$ (the y-intercept of Fig. 4) is an offset determined by the magnetic field rise time of $70 \mathrm{~ms}$, the layer of thermal grease and the temperature sensor. It is important to note that the response time reported by Lakeshore $(\mathrm{t}=$ $135 \mathrm{~ms}$ at $273 \mathrm{~K}$ ) is the sensor rise time, not the time constant. The slope of the line $\left(a=g C_{2}=0.11 \mathrm{Jm}^{-1} \mathrm{~K}^{-1}\right)$ is proportional to the heat capacity of the temperature sensor $\left(C_{2}\right)$.

The experimental $\tau$ values (circles of Fig. 4) reported in Table 1 are an average of the values obtained by fitting hundreds of subsequent thermomagnetic cycles (see fits reported in Fig. 3) for each studied material (including separate measurements where the sample was removed from the sample holder and then remounted). The error bars shown here reflect the statistical variation in the data.

The outcome of Fig. 4 is that under Brayton cycle conditions the thermal transport properties dominate the determination of the $\Delta T_{\text {ad }}$ curves, 


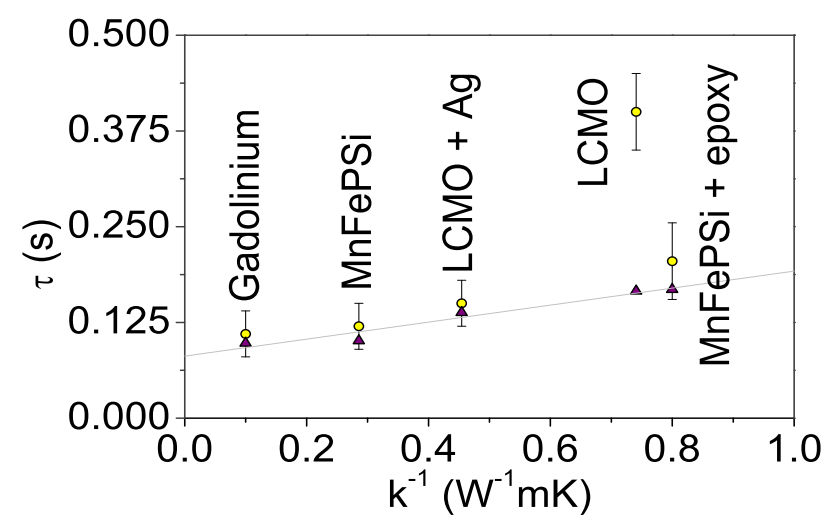

Figure 4: (Color online) Temperature change time constants $(\tau)$ from experiments (circles) and heat transfer simulations (triangles) as a function of $\frac{1}{k}$.

and thus limit the maximum cycle frequency, in the case of gadolinium, Mn$\mathrm{FePSi}, \mathrm{LCMO}+\mathrm{Ag}$ and $\mathrm{MnFePSi}+$ epoxy. This result recalls the recent report of Lovell et al., where the dynamics of the first order metamagnetic transition in $\mathrm{La}(\mathrm{Fe}, \mathrm{Si})_{13}$ was studied (Lovell et al., 2014). For strongly first order materials, Lovell et al. found that the transition time for the material to evolve from one phase to the other was dominated by nucleation and growth when the field sweep rate was slow (below $5 \mathrm{mTs}^{-1}$ ). The precise form of the transition under these conditions was influenced greatly by the sample shape, size, and demagnetizing fields. When the sweep rate was faster, Lovell et al., found that the thermal connectivity across the thinnest dimension dominated the dynamic behavior of the transition in LaFeSi. The observations in our manuscript strongly support these suggestions. Our observations are on different materials and we use different experimental methods to arrive at a similar conclusion under much faster magnetic field rates $\left(10 \mathrm{Ts}^{-1}\right)$. The parent LCMO is on the other hand an outlier: its experimental time constant 
is about $250 \mathrm{~ms}$ higher than the time constant obtained from heat transfer simulations. This aspect will be investigated in detail in future, however the data presented here allows us to draw some preliminary conclusions.

The addition of silver to the parent LCMO matrix may be a key to implement these materials in future solid-state energy conversion devices operating at high frequencies.

Ag-filled and parent LCMO have the same stoichiometry and tolerance factor since they were prepared from the same polycrystalline powders (Turcaud et al., 2013). This aspect supports the idea that the origin of the slower response reported for the parent LCMO may be linked with a markedly different behaviour at the length scale of the grain boundaries. Turcaud carried out electrical resistivity measurements and showed that the addition of silver removed parasite resistance from the grain boundaries restoring the characteristic shape of the metal-insulator transition (Turcaud et al., 2013). We believe that this is one of the paths to investigate in order to explain why the parent LCMO departs from the general behaviour followed by the other materials.

\section{Conclusions}

Reports on the dynamics of a material's magnetocaloric response are still very limited. Here we directly measure and simulate the MCE when the material is driven by fast magnetic field changes to study the impact of the material's thermal conductivity on the time constant of the temperature change, $\tau$. The experimental results, coherent with the recent outcomes of Lovell et al., are in agreement with an effective model developed to show the 
relation between $\tau$ and the material's thermal properties.

The addition of silver to the parent LCMO matrix reduced $\tau$ markedly. The parent LCMO, however, exhibited a time constant significantly higher than that predicted by thermal simulations $(\tau=0.40 \pm 0.05 \mathrm{~s}$ is approximately $0.25 \mathrm{~s}$ higher than expected from heat transfer simulations). This feature seems to indicate additional contributions to the dynamic response in the case of LCMO. The origin of this discrepancy in the manganite samples could be a result of poor inter-grain properties or the dynamics of the phase transition itself and will be the focus of future work.

The developed experimental and theoretical insight provides a useful tool to estimate the response time of magnetocaloric materials when used in cooling devices. The study of the time constant of temperature change puts an upper bound to determination of a material's maximum cycle frequency.

\section{Acknowledgements}

The authors wish to acknowledge K. G. Sandeman, G. Allodi and Dr. M. Mazzani for useful discussions. Fondazione Angelo Della Riccia, the Physics and Earth Sciences Department of University of Parma and the Dutch foundation for Fundamental Research on Matter (FOM) offered financial support to G. Porcari. This work was supported by the UK EPSRC Programme grant, Nanostructured functional materials for Energy Efficient Refrigeration (EP/G060940). This work is a part of an Industrial Partnership Program of the Dutch foundation for Fundamental Research on Matter (FOM), financed by BASF New Business. 
Bahl C. R. H., Petersen T. F., Pryds N., Smith A., 2008. A versatile magnetic refrigeration test device. Rev. Sci. Instrum. 79, 093906.

Bahl C. R. H., Velázquez D., Nielsen K. K., Engelbrecht K., Andersen K. B., Bulatova R., Pryds N., 2012. High performance magnetocaloric perovskites for magnetic refrigeration. Appl. Phys. Lett. 100, 121905.

Brück E., 2005. Developments in magnetocaloric refrigeration. J. Phys. D: Appl. Phys. 38, R381-R391.

Czernuszewicz A., Kaleta J., Lewandowski D., Przybylski M., 2014. An idea of the test stand for studies of magnetobarocaloric materials properties and possibilities of their application. Phys. Status Solidi (c) 11, 995-999.

Dinesen A. R., Linderoth S., Mørup S. 2005. Direct and indirect measurement of the magnetocaloric effect in $\mathrm{La}_{0.67} \mathrm{Ca}_{0.33-x} \mathrm{Sr}_{x} \mathrm{MnO}_{3 \pm \delta}(\mathrm{x} \in[0 ; 0.33]) \mathrm{J}$. Phys.: Condens. Matter 17, 6257-6269.

Dung N. H., Ou Z. Q., Caron L., Zhang L., Thanh D. T. C., de Wijs G. A., de Groot R. A., Buschow K. H. J., Brück E., 2011. Mixed Magnetism for Refrigeration and Energy Conversion. Adv. Energy Mater. 1, 1215-1219.

Fähler S., Rößler U. K., Kastner O., Eckert J., Eggeler G., Emmerich H., Entel P., Müller S., Quandt E., Albe K., 2012. Caloric Effects in Ferroic Materials: New Concepts for Cooling. Adv. Eng. Mater. 14, 10-19.

Franco V., Blázquez J. S., Ingale B., Conde A., 2012. The magnetocaloric effect and Magnetic Refrigeration Near Room Temperature: Materials and Models. Annu. Rev. Mater. Res. 42, 305-342. 
Furukawa G. T., Saba W. G., Reilly M. L., 1968. NSRDS 18 Critical Analysis of the Heat-Capacity Data of the Literature and Evaluation of Thermodynamic Properties of Copper, Silver, and Gold from 0 to 300 K. NSRDSNBS 18, 49p.

Guillou F., Porcari G., Yibole H., van Dijk N., Brück E., 2014. Taming the First-Order Transition in Giant Magnetocaloric Materials. Adv. Mater. 26, 2671-2675.

Guillou F., Yibole H., Porcari G., Zhang L., van Dijk N. H., Brück E., 2014. magnetocaloric effect, cyclability and coefficient of refrigerant performance in the $\mathrm{MnFe}(\mathrm{P}, \mathrm{Si}, \mathrm{B})$ system. J. Appl. Phys. 116, 063903.

Gutfleisch O., Willard M. A., Brück E., Chen C. H., Sankar S. G., Liu J. P., 2011. Magnetic Materials and Devices for the 21st Century: Stronger, Lighter, and More Energy Efficient. Adv. Mater. 23, 821-842.

Hu F. X., Shen B. G., Sun J. R., Cheng Z. H., Rao G. H., Zhang X. X., 2001. Influence of negative lattice expansion and metamagnetic transition on magnetic entropy change in the compound $\mathrm{LaFe}_{11.4} \mathrm{Si}_{1.6}$. Appl. Phys. Lett. 78, 3675-3677.

Incropera F. P., Dewitt D. P., Bergman T. L., Lavine A. S., 2007. Fundamentals of Heat and Mass Transfer (6th Edition). John Wiley, New York.

Kamarád J., Kaštil J., Arnold Z., 2012. Practical system for the direct measurement of magneto-caloric effect by micro-thermocouples. Rev. Sci. Instrum. 83, 083902. 
Krenke T., Duman E., Acet M., Wassermann E. F., Moya X., Mañosa L., Planes A., 2005. Inverse magnetocaloric effect in ferromagnetic Ni-Mn-Sn alloys. Nature Mater. 4, 450-454.

Kuz'min M. D., 2007. Factors limiting the operation frequency of magnetic refrigerators. Appl. Phys. Lett. 90, 251916.

Legait U., Guillou F., Kedous-Lebouc A., Hardy V., Almanza M., 2014. An experimental comparison of four magnetocaloric regenerators using three different materials. Int. J. Refrigeration 37, 147-155.

Lovell E., Pereira A. M., Caplin A. D., Lyubina J., Cohen L. F., 2014. Dynamics of the First-Order Metamagnetic Transition in Magnetocaloric $\mathrm{La}(\mathrm{Fe}, \mathrm{Si})_{13}$ : Reducing Hysteresis. Adv. Energy Mater. doi: 10.1002/aenm.201401639.

Lyubina J., Schäfer R., Martin N., Schultz L., Gutfleisch O., 2010. Novel Design of $\mathrm{La}(\mathrm{Fe}, \mathrm{Si})_{13}$ Alloys Towards High Magnetic Refrigeration Performance. Adv. Mater. 22, 3735-3739.

Lyubina J., 2011. Recent advances in the microstructure design of materials for near room temperature magnetic cooling (invited). J. Appl. Phys. 109, 07A902.

Mañosa L., González-Alonso D., Planes A., Bonnot E., Barrio M., Tamarit J.-L., Aksoy S., Acet M., 2010. Giant solid-state barocaloric effect in the Ni-Mn-In magnetic shape-memory alloy. Nature Mater. 9, 478-481.

Mañosa L., Jarque-Farnos S., Vives E., Planes A., 2013. Large temperature 
span and giant refrigerant capacity in elastocaloric $\mathrm{Cu}-\mathrm{Zn}-\mathrm{Al}$ shape memory alloys. Appl. Phys. Lett. 103, 211904.

Moore J. D., Morrison K., Sandeman K. G., Katter M., Cohen L. F., 2009. Reducing extrinsic hysteresis in first-order $\mathrm{La}(\mathrm{Fe}, \mathrm{Co}, \mathrm{Si})_{13}$ magnetocaloric systems. Appl. Phys. Lett. 95, 252504.

Moore J. D., Klemm D., Lindackers D., Grasemann S., Träger R., Eckert J., Löber L., Scudino S., Katter M., Barcza A., Skokov K. P., Gutfleisch O., 2013. Selective laser melting of $\mathrm{La}(\mathrm{Fe}, \mathrm{Co}, \mathrm{Si})_{13}$ geometries for magnetic refrigeration. J. Appl. Phys. 114, 043907.

Moya X., Stern-Taulats E., Crossley S., Gonzalez-Alonso D., Kar-Narayan S., Planes A., Mañosa L., Mathur N. D., 2013. Giant Electrocaloric Strength in Single-Crystal BaTiO 3 . Adv. Mater. 25, 1360-1365.

Moya X., Kar-Narayan S., Mathur N. D., 2014. Caloric materials near ferroic phase transitions. Nature Mater. 13, 439-450.

Nielsen K. K., Engelbrecht K., 2012. The influence of the solid thermal conductivity on active magnetic regenerators. J. Phys. D: Appl. Phys. 45, 145001.

Narumanchi S., Mihalic M., Kelly K., Eesley, G., 2008. Thermal interface materials for power electronics applications. ITHERM 11, 395-404.

Ozbolt M., Kitanovski A., Tusek J., Poredos A., 2014. Electrocaloric refrigeration: Thermodynamics, state of the art and future perspectives. Int. J. Refrigeration 40, 174-188. 
Pecharsky V. K., Gschneidner Jr. K. A., Pecharsky A. O., Tishin A. M. 2001. Thermodynamics of the magnetocaloric effect. Phys. Rev. B 64, 144406.

Pecharsky V. K., Gschneidner Jr. K. A., 1997. Giant magnetocaloric effect in $\mathrm{Gd}_{5}\left(\mathrm{Si}_{2} \mathrm{Ge}_{2}\right)$. Phys. Rev. Lett. 78, 4494-4497.

Porcari G., Buzzi M., Cugini F., Pellicelli R., Pernechele C., Caron L., Brück E., Solzi M., 2013. Direct magnetocaloric characterization and simulation of thermomagnetic cycles. Rev. Sci. Instrum. 84073907.

Sandeman K. G., 2011. Gas-free refrigeration, In Magnetics Technology International, 30-32.

Sandeman K. G., 2012. Magnetocaloric materials: The search for new systems. Scr. Mater. 67, 566-571.

Smith A., Bahl C. R. H., Bjørk R., Engelbrecht K., Nielsen K. K., Pryds N., 2012. Materials Challenges for High Performance Magnetocaloric Refrigeration Devices Adv. Energy Mater. 2, 1288-1318.

Tegus O., Brück E., Buschow K. H. J., de Boer F. R., 2002. Transitionmetal-based magnetic refrigerants for room-temperature applications. Nature (London) 415, 150-152.

Tishin, A.M., Spichkin, Y.I., 2003. The Magnetocaloric Effect and Its Applications. Institute of Physics Publishing, Bristol, 476 pp.

Trung N. T., Biharie V., Zhang L., Caron L., Buschow K. H. J., Brück E., 2010. From single- to double-first-order magnetic phase transition in magnetocaloric $\mathrm{Mn}_{1-x} \mathrm{Cr}_{x}$ CoGe compounds. Appl. Phys. Lett. 96, 162507. 
Turcaud J. A., Morrison K., Berenov A., Alford N. McN., Sandeman K. G., Cohen L. F., 2013. Microstructural control and tuning of thermal conductivity in $\mathrm{La}_{0.67} \mathrm{Ca}_{0.33} \mathrm{MnO}_{3 \pm \delta}$. Scripta Mater. 68, 510-513.

Turcaud J. A., Pereira A. M., Sandeman K. G., Amaral J. S., Morrison K., Berenov A., Daoud-Aladine A., Cohen L. F., 2014. Spontaneous magnetization above $\mathrm{T}_{\mathrm{C}}$ in polycrystalline $\mathrm{La}_{0.7} \mathrm{Ca}_{0.3} \mathrm{MnO}_{3}$ and $\mathrm{La}_{0.7} \mathrm{Ba}_{0.3} \mathrm{MnO}_{3}$. Phys. Rev. B 90, 024410.

Wada H., Tanabe Y., 2001. Giant magnetocaloric effect of $\mathrm{MnAs}_{1-x} \mathrm{Sb}_{x}$. Appl. Phys. Lett. 79, 3302-3304.

Yibole H., Guillou F., Zhang L., van Dijk N. H., Brück E., 2014. Direct measurement of the magnetocaloric effect in $\mathrm{MnFe}(\mathrm{P}, \mathrm{X})(\mathrm{X}=\mathrm{As}, \mathrm{Ge}, \mathrm{Si})$ materials. J. Phys. D: Appl. Phys. 47, 075002. 